\title{
Evaluation of new surfactants for enhanced oil recovery applications in high-temperature reservoirs
}

\author{
Nazliah Nazma Zulkifli ${ }^{1,2}$. Syed M. Mahmood ${ }^{1} \cdot$ Saeed Akbari ${ }^{1} \cdot$ Arif Azhan A. Manap $^{2} \cdot$ Nor Idah Kechut $^{2}$. \\ Khaled Abdalla Elrais ${ }^{1}$
}

Received: 2 November 2018 / Accepted: 10 June 2019 / Published online: 26 June 2019

(c) The Author(s) 2019

\begin{abstract}
Surfactants have been successfully used for enhanced or improved oil recovery in reservoirs having mild conditions (low temperature, low salinity). Reservoirs having harsh conditions, however, offer unique challenges in that most surfactants precipitate and chemically degrade due to a combined effect of high temperature and hardness salinity. Industry's efforts are continuing to develop or formulate surfactants for oil recovery applications to high temperature and salinity. The aim of this study was to evaluate several modified anionic surfactants/formulations that were claimed to be able to overcome the unfavorably high-salinity brine (sea water) and high temperature and to understand the impact of high temperature to surfactant adsorption. A series of experiments were conducted to characterize and quantify the effects of aging time in high temperature $\left(106^{\circ} \mathrm{C}\right)$ and seawater salinity $(32,000 \mathrm{ppm}$ with 1600 hardness) on surfactant performance. Results for both sulfate- and sulfonate-based surfactants were deemed not to be satisfactory. Sulfate-based surfactants encountered hydrolysis problem at high temperature, whereas sulfonate-based surfactants precipitated in the presence of divalent ions. This study then focused on alkyl ether carboxylate (AEC) as the main surfactant, and blends of AEC with alkyl polyglucoside (APG). To find the optimum conditions, phase behavior tests were performed with a fixed seawater salinity but with different blending ratios of surfactant and co-surfactant, as well as overall surfactant concentrations, similar to the salinity scan. Type III microemulsion was observed for both surfactant solutions of AEC and AEC-APG blend with IFT of $10^{-3} \mathrm{mN} / \mathrm{m}$ (millinewton/meter). Surfactant adsorption resulted in lower adsorption in the high-temperature region. The results of this project are urgently needed by the industry for future screening in order to find suitable surfactants for applying to reservoirs with harsh conditions. The study also intends to provide an understanding of adsorption relationship to high temperature, as a guideline in addressing surfactant losses due to adsorption at high-temperature field application.
\end{abstract}

Keywords Chemical enhanced oil recovery $\cdot$ High temperature $\cdot$ High salinity $\cdot$ Surfactant adsorption

\section{Introduction}

Surfactants are widely used and have a very large number of applications, especially in the petroleum industry for enhanced oil recovery (EOR) process because of their ability to influence the properties of the rock surface and oil-water interface (Puerto et al. 2012; Lu et al. 2014; Hesham et al.

Nazliah Nazma Zulkifli

nazliah.zulkifli@petronas.com.my

1 Petroleum Engineering Department, Universiti Teknologi PETRONAS, Persiaran UTP, 32610 Seri Iskandar, Perak, Malaysia

2 Kawasan Institusi Bangi, Petronas Research Sdn. Bhd. (PRSB), 43000 Kajang, Selangor, Malaysia
2018). Surfactant is a surface acting agent, and they can adsorb at a surface of the fluid-fluid interface to alter the surface properties significantly, thus reducing the surface tension and interfacial tension (Hocine et al. 2016). The interfacial or surface tension is a measure of the difference in nature where the two phases are meeting at the interface or surface; the higher the dissimilarity in their natures, the higher the interfacial tension or surface tension between them (Rosen 2004; Hadian et al. 2018; Hematpur et al. 2017). Surfactant has a molecular structure that consists of a hydrophilic group which has a strong attraction to the solvent and the hydrophobic group, which has very little attraction to solvent. Surfactant is classified depending on the nature of the hydrophilic part. These classes are anionic, cationic, zwitterionic, and non-ionic (Sheng 2011). 
There are two surfactant mechanisms in EOR process application, which are lowering the interfacial tension (IFT) and emulsification of oil and water (Bevlere et al. 1988). Surfactants are used to reduce interfacial tension, which leads to an additional mobilization of oil trapped by capillary forces in the rock matrix. In the reservoir, trapped oil droplets (residual oil) cannot be displaced due to the high energy required to overcome capillary pressure $(\mathrm{Pc})$ under normal oil-water IFT. The surfactant is used to overcome this problem since it is capable of reducing oil-water interfacial tension from $10-30 \mathrm{mN} / \mathrm{m}$ to $0.001 \mathrm{mN} / \mathrm{m}$. By lowering oil-water IFT, capillary number $(\mathrm{Nc})$ will increase. Thus, oil droplet can be displaced easier and increase oil recovery. The capillary number for strongly water-wetting media can be calculated, as shown in Eq. (1) (Chatzis and Morrow 1984):

$\mathrm{Nc}=\nu \mu / \sigma$,

where $v$ is the Darcy velocity $(\mathrm{m} / \mathrm{s}), \mu$ is the dynamic viscosity of the liquid ( $\mathrm{mPa} \mathrm{s}$ ), $\sigma$ is the interfacial tension between fluids $(\mathrm{mN} / \mathrm{m})$, and $\mathrm{Nc}$ is the capillary number (dimensionless).

In EOR methods involving surfactant injection, critical micellar concentration (CMC) is important for IFT reduction and surfactant adsorption. IFT reduction will be increased by surfactant concentration. However, the reduction will be stopped after reaching CMC, as schematically shown in Fig. 1 and reported in the literature (Sheng 2011; Kamal et al. 2017). Moreover, the surfactant adsorption will be increased by surfactant concentration to the CMC point, in which maximum adsorption will occur. After CMC, adsorption will be stopped, and cumulative adsorption will reach the plateau region (Schramm 2000; Hamed et al. 2018).

At low surfactant concentrations, most of the solution properties are similar to the simple electrolyte, but at higher surfactant concentration, unusual changes are observed which can be used for CMC determination. For EOR

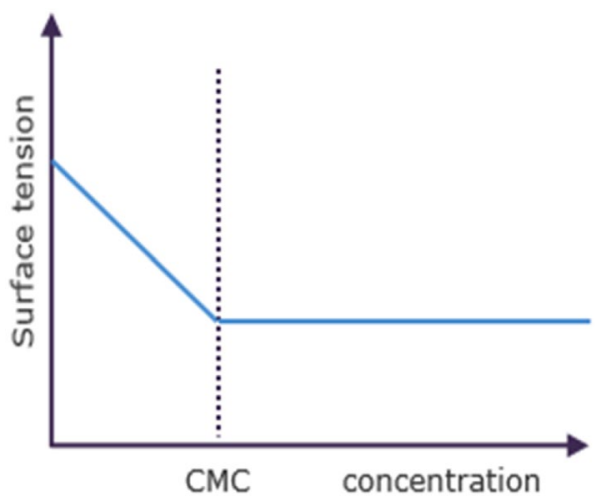

Fig. 1 Schematic of the concentration dependence of surface tension for the solution of a micelle-forming surfactant surfactant, CMC determination has been commonly made by measuring the surface tension or interfacial tension as a function of surfactant concentration. Before reaching CMC, the surfactant is adsorbed at the oil-water interface; thus, interfacial tension keeps reducing by surfactant concentration. After reaching CMC, however, there is no further reduction in interfacial tension by surfactant concentration. It is due to the fact that at CMC point, micelles start to form and aggregate in the liquid phase. By increasing the surfactant concentration above $\mathrm{CMC}$, surfactant molecules will move to the liquid phase and form more micelles instead of moving to the surface and reduction in IFT (Schramm 2000).

Addition of surfactant in injection brine will cause emulsification of oil in water. In EOR, the microemulsion is a stable translucent micellar solution of oil and water. Types of microemulsion and salinity effect on phase behavior will determine the potential surfactant formulation for EOR processes (Southwick et al. 2016). The purpose of the phase behavior test is to determine the chemical formulation for a specific application. In practice, the range of salinity is studied to find the relative surfactant solubility in brine and oil. Optimum salinity is targeted for EOR formulation, where the surfactant is equally soluble in oil and brine, which results in the lowest IFT between oil and brine.

However, a study on modified phase behavior test also can be done for a fixed salinity application, and more hydrophilic and more hydrophobic surfactants are mixed in different ratios to produce under optimum, optimum, and over optimum conditions similar to salinity scan (Southwick et al. 2016). For a fixed water salinity application, such as seawater application as the injection water, modified phase behavior test can be done to determine optimum surfactant formulation for a typical field condition (i.e., fixed water salinity). The present study focused on fixed salinity, where seawater is used as brine for surfactant mixture. The optimum ratio of the main surfactant (AEC) and co-surfactant (APG) is identified based on modified phase behavior.

The high potential of surfactant-based flooding has been demonstrated in favorable conditions, such as at low temperature and soft brines. However, there are a very limited number of surfactants available that can be applied under harsh conditions of high temperature $\left(>100{ }^{\circ} \mathrm{C}\right)$ and high salinity/hardness. Sulfates surfactant can improve surfactant tolerance to high salinities. However, they are subjected to hydrolysis at high temperature because it has sulfur-to-oxygen bond. Sulfonate surfactants such as olefin sulfonates and alkyl benzene sulfonates are stable at high temperature but sensitive to divalent ions (Abbas et al. 2017). Sulfonates are stable at high temperatures because they have sulfurto-carbon bond, which is not easily subjected to hydrolysis.

At high temperature, the performance of surfactant-based flooding can be drastically decreased due to the instability of the applied surfactant. Chemically and the thermally 
stable surfactant is required to be identified, and its performance is mandatory to be evaluated for chemical EOR applications. Chemical stability is whether the surfactant molecule degrades under specified targeted condition, whereas solubility is whether surfactant dissolved and does not precipitate in the solution (Jurgenson et al. 2015; Morel et al. 2016; Adkins et al. 2012). The addition of co-solvent or co-surfactant enables the surfactant solution to be prepared with a concentrated brine solution, even at high divalent cations concentration (Bevlere et al. 1988). The biggest impediment to the use of a thermally stable surfactant in chemical EOR is the very poor solubility and compatibility of these surfactants in water containing high divalent cations such as calcium and magnesium, especially at high temperature where the solubility and compatibility are drastically reduced. Thus, this study is meant to identify workable surfactant formulation at harsh field conditions and also to find a co-surfactant and an optimum ratio for blending surfactant system that can improve the selected surfactant's compatibility with brine, chemically and thermally stable.

The cost of the surfactant is one of the most expensive items in the total cost of chemical EOR project. One of the criteria for economic success is minimizing the surfactant loss due to adsorption. Therefore, the knowledge of surfactant adsorption is critical and needs to be studied, especially at high temperature. Adsorption refers to a collection of molecules on the surfaces, either internal or external of liquids or solids (Dabrowski 2001). During transportation through porous media, surfactant molecules tend to aggregate on the surface of the rock which lowers the initial surfactant concentration. To evaluate surfactant adsorption, the difference in initial surfactant concentration to final concentration during flooding is measured. This difference is converted to the gram of surfactant and divided by gram of rock to determine adsorption value $(\mathrm{g} / \mathrm{g})$. Reviewing previous publications showed that most of the adsorption researches had been focused on a relatively low temperature and adsorption at high temperature $\left(>100^{\circ} \mathrm{C}\right)$ has been ignored. Therefore, this study intends to fill the gap and systematically experiment the effect of high temperature on adsorption and provides a guideline in addressing surfactant losses due to adsorption at high temperature.

\section{Materials and methods}

\section{Materials}

Surfactants that were used in this study are alkyl ether carboxylate (AEC) and alkyl polyglucoside (APG). The general structure of each surfactant is shown in Fig. 2. The carboxylate surfactant functionality will promote temperature stability, and there are established methods to introduce this hydrophilic headgroup in alkyl alkoxylates. It has outstanding tolerance against high temperatures and high salinity while delivering high interfacial activity ( $\mathrm{Lu}$ et al. 2014; Jun et al. 2014). Anionically modified APG was used as cosurfactant, because it has excellent tolerance against salinity hardness due to its hydrophilic glucose moiety, and improves AEC solubility (Jurgenson et al. 2015). Table 1 shows the
Fig. 2 General chemical structure of used surfactants: a alkyl ether carboxylate (AEC), b alkyl polyglucosides (APG)

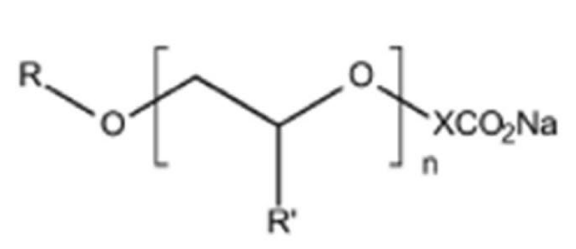

(a)

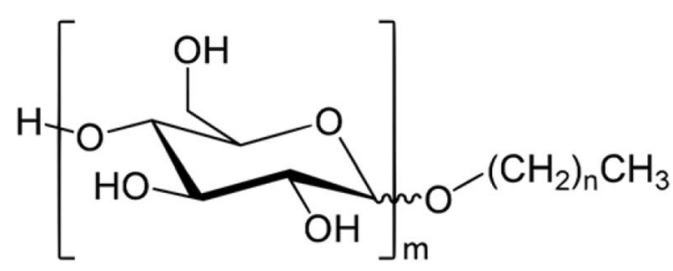

(b)
Table 1 Properties of alkyl ether carboxylate and alkyl polyglucoside surfactants obtained from the supplier

\begin{tabular}{|c|c|c|c|}
\hline Surfactant & Type & Key properties & Supplier \\
\hline Alkyl ether carboxylate (AEC) & Anionic surfactant & $\begin{array}{l}\text { Appearance: yellowish, } \\
\text { viscous, liquid } \\
\text { pH: } 7.1 \\
\text { Density: } 1.0241 \mathrm{~g} / \mathrm{cm}^{3} \\
\text { at } 23^{\circ} \mathrm{C} \\
\text { Active matter }(\%): 45\end{array}$ & BASF \\
\hline Alkyl polyglucoside (APG) & Anionic surfactant & $\begin{array}{l}\text { Appearance: yellowish, } \\
\text { liquid. } \\
\text { pH: } 8.5 \\
\text { Density: } 1.109 \mathrm{~g} / \mathrm{cm}^{3} \text { at } \\
23^{\circ} \mathrm{C} \\
\text { Active matter }(\%): 51.5\end{array}$ & BASF \\
\hline
\end{tabular}


Table 2 Sea water composition

\begin{tabular}{lllll}
\hline No. & Test description & Unit & Test methods & Analysis \\
\hline 1 & pH at 20 ${ }^{\circ} \mathrm{C}$ & - & APHA 4500 $\mathrm{H}$ & 7.76 \\
2 & Conductivity & $\mathrm{uS} / \mathrm{cm}$ & APHA 2510B & 49,537 \\
3 & Salinity & $\mathrm{mg} / \mathrm{L}$ & APHA 2520B & 32,390 \\
4 & Total dissolved solids & $\mathrm{mg} / \mathrm{L}$ & APHA 2540C & 35,200 \\
6 & Density @ 20 ${ }^{\circ} \mathrm{C}$ & $\mathrm{g} / \mathrm{cm}^{4}$ & ASTM 4052 & 1.0237 \\
8 & Sulfate, $\mathrm{SO}_{4}{ }^{2-}$ & $\mathrm{mg} / \mathrm{L}$ & HACH 8051 & 2000 \\
9 & Chloride, $\mathrm{Cl}^{-}$ & $\mathrm{mg} / \mathrm{L}$ & APHA 4500Cl-B & $18,520.85$ \\
10 & Bicarbonate, $\mathrm{HCO}_{3-}$ & $\mathrm{mg} / \mathrm{L}$ & APHA 2320 B & 148.29 \\
11 & Carbonate, $\mathrm{CO}_{3}^{-2}$ & $\mathrm{mg} / \mathrm{L}$ & APHA 2320 B & 0 \\
12 & Hydroxide, $\mathrm{OH}^{-}$ & $\mathrm{mg} / \mathrm{L}$ & APHA 2320 B & 0 \\
& & & Total Anion & $20,669.14$ \\
13 & Iron, Fe & $\mathrm{mg} / \mathrm{L}$ & APHA 3120B & 0 \\
14 & Sodium, $\mathrm{Na}$ & $\mathrm{mg} / \mathrm{L}$ & APHA 3120B & 10,080 \\
15 & Calcium, $\mathrm{Ca}$ & $\mathrm{mg} / \mathrm{L}$ & APHA 3120B & 380 \\
16 & Magnesium, $\mathrm{Mg}$ & $\mathrm{mg} / \mathrm{L}$ & APHA 3120B & 1222 \\
17 & Potassium, $\mathrm{K}$ & $\mathrm{mg} / \mathrm{L}$ & APHA 3120B & 368.5 \\
18 & Strontium, $\mathrm{Sr}$ & $\mathrm{mg} / \mathrm{L}$ & APHA 3120B & 6.456 \\
19 & Barium, $\mathrm{Ba}$ & $\mathrm{mg} / \mathrm{L}$ & APHA 3120B & 0 \\
& & & Total cations & $12,056.956$ \\
\hline
\end{tabular}

available information for the surfactants, which was provided by the supplier and has not independently verified. Table 2 shows the composition of injected water, which was mixed with the above-mentioned surfactants.

\section{Experimental procedure}

This study involved surfactant screening in monitoring the surfactant performance at high-temperature and highsalinity/hardness conditions. Surfactant screening criteria involved solubility at high temperature, interfacial tension test, microemulsion phase behavior, and thermal stability. After finding the optimum surfactant solution composition, the selected formulations were tested for their adsorption relationship with temperature.

Surfactant screening was started by close observation of the surfactant solution solubility and compatibility at elevated temperatures $\left(80{ }^{\circ} \mathrm{C}\right.$ and $\left.106{ }^{\circ} \mathrm{C}\right)$ to simulate actual challenging reservoir conditions. Optimum surfactant formulation in surfactant flooding desires to be compatible with the applied solvent (sea water in this study) and avoid precipitation problem and also to ensure the good performance of the whole process. In this study, only two variables of surfactant concentration and surfactant/co-surfactant ratio were adjusted to find the best possible surfactant formulation. In addition, the proposed surfactant formulation requires to be chemically stable for a period of time for high-temperature application (Zhou et al. 2013). The surfactant solubility and compatibility were assessed, and non-soluble composition was identified if the surfactant solution showed cloudiness, phase separation, and precipitation.

\section{Oxygen control preparation}

The surfactant screening test was done in the oxygen control condition to avoid oxygen presence in the system. In fact, the surfactant may quickly oxidize at high temperature and, therefore, lose its property (Sheng 2011). Besides, it is a must to remove the oxygen from the system to have a similar condition to the reservoir since most of the oil reservoirs are in anaerobic, reducing environment (Akbari et al. 2017). Therefore, for laboratory testing, the chemical preparations were in the oxygen control condition where we removed dissolved oxygen from the solution. To do so, a specific procedure was followed. Firstly, the prepared surfactant solutions were vacuumed and purged with nitrogen to remove the dissolved oxygen for at least $2 \mathrm{~h}$, with the alternate cycle of nitrogen and vacuum flow (setup is shown in Fig. 3). Then, the samples were transferred into an automated glove box (MBRAUN) as shown in Fig. 4 to further reduce dissolved oxygen and to ensure the surfactant samples and the
Fig. 3 De-gas (vacuum) and nitrogen purging setup

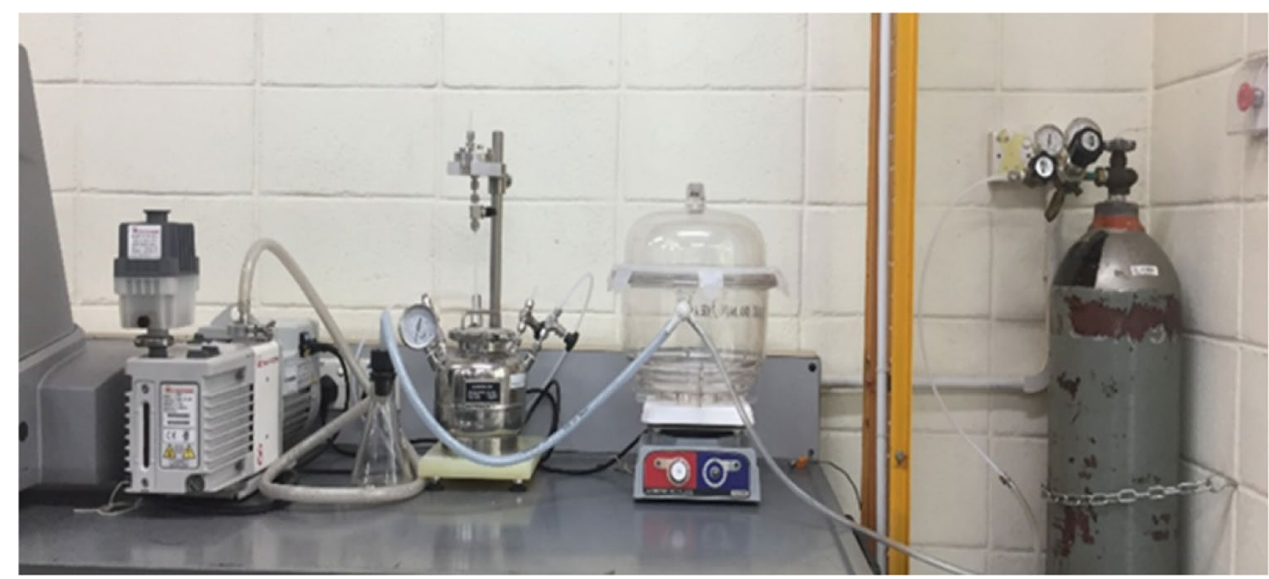


Fig. 4 MBRAUN glove box

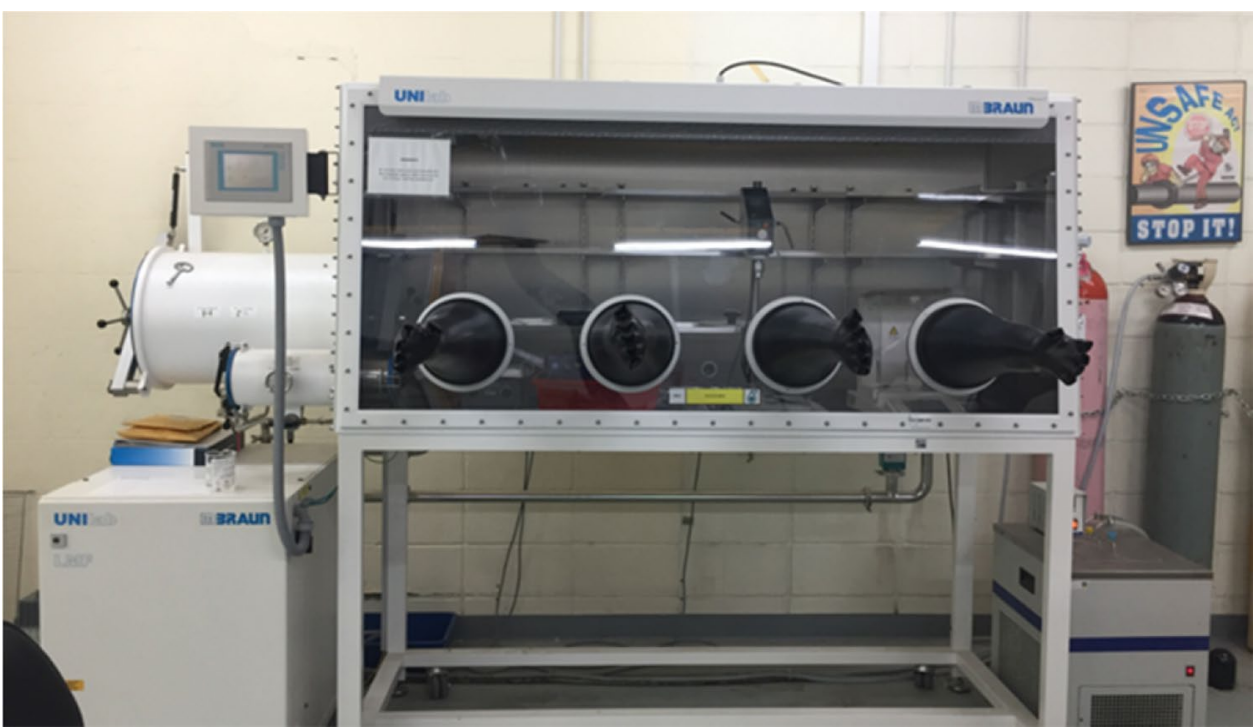

environment is in oxygen-free condition. Oxygen content was monitored using a dissolved oxygen probe (CHEMets ${ }^{\circledR}$ Visual Kit) to assure that the oxygen content is less than $50 \mathrm{ppb}$ (part per billion).

For long-term thermal stability and adsorption test, surfactant solutions were stored in glass ampoules. Ampoules containing surfactant solutions were sealed using fire to avoid solution evaporation and dried out at high temperature. Figure 5 shows the vacuum and nitrogen purging setup for ampoules fire sealing. Alternate nitrogen purging and vacuum flow were applied for the solution for $2 \mathrm{~h}$.

\section{Solubility and compatibility}

Surfactant solutions stock was received from BASF chemical supplier. Diluted surfactant solution was prepared by using dilution Eq. (2), and the active percent for each stock surfactant is considered.

Dilution equation $=\mathrm{M} 1 \mathrm{~V} 1 / \mathrm{M} 2 \mathrm{~V} 2$,

where M1 is the concentration in molarity (moles/liters) of the concentrated solution, V1 is the volume of the concentrated solution, M2 is the concentration in molarity of the dilute solution (after more solvent has been added), and V2 is the volume of the dilute solution.

Surfactant and co-surfactant were mixed at predetermined concentrations and various ratios of surfactant: cosurfactant $(80: 20,70: 30,60: 40$, and 50:50), to determine
Fig. 5 Vacuum and nitrogen purging setup for fire sealing

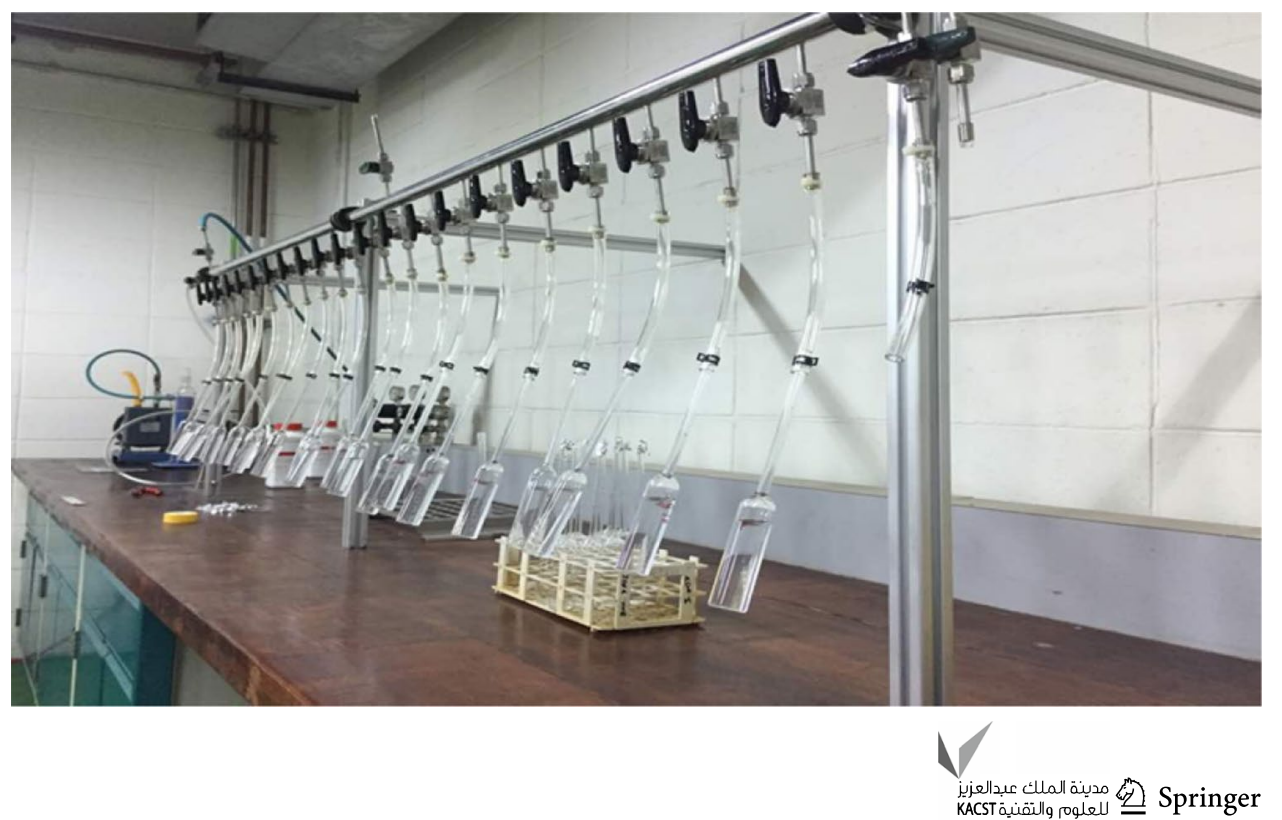


the most compatible and soluble surfactant solution for further test. Surfactants were prepared in saline seawater brines at elevated temperatures, to simulate challenging reservoir conditions. Surfactant solution has a high tendency to precipitate in seawater brine with high divalent cations. Therefore, in order to ensure good performance of the surfactant, good solubility and compatibility of surfactant with injected brines are critical. The surfactant solutions were physically observed for its stability and compatibility up to 60 days. Surfactant solubility and compatibility were assessed, and non-soluble composition was identified if the surfactant solution showed cloudiness, phase separation, and precipitation.

\section{Phase behavior test}

Microemulsion phase behavior study was then tested to identify optimum surfactant formulation. For this particular study, tests were performed at high temperature using seawater injection brine as a solvent, which contains divalent ions (hardness). The test was conducted by adding the surfactant solution in reservoir crude oil in the tubes, and then mixed thoroughly and allowed to equilibrate. Equilibrium between the surfactant and crude oil had been quantified by visual inspection of phase behavior such as microemulsion phase shift, phase volume, color transparency of aqueous phase until it has no change for at least 2 weeks in elevated

Table 3 Crude oil properties

\begin{tabular}{llll}
\hline No. & Test description & Unit & Results \\
\hline 1 & Volatiles & mass\% & 75 \\
2 & $\begin{array}{l}\text { Asphaltene and inorganic (n-pen- } \\
\text { tane insoluble) }\end{array}$ & mass\% & 0.06 \\
& Saturates & mass\% & 18 \\
3 & Aromatics & mass\% & 4.7 \\
4 & Resins & mass\% & 0.16 \\
5 & Wax content & mass\% & 6.3 \\
6 & Kinematic viscosity @ $90^{\circ} \mathrm{C}$ & $\mathrm{mm}^{2} / \mathrm{s}$ & 1.047 \\
7 & & & \\
\hline
\end{tabular}

temperatures. The properties of the oil type, which were used in this study, are provided in Table 3.

In this study, since it is a fixed water salinity application where the injection water is seawater, a modified phase behavior test was applied. In this test, a surfactant and cosurfactant solutions were mixed at different ratios. The total surfactant solutions were added into crude oil to produce under optimum, optimum, and over optimum conditions similar to traditional salinity scan to determine optimum surfactant formulation (Southwick et al. 2016). For EOR purposes, the best phase type is Type III, followed by Type I and Type II, according to Windsor (Sheng 2011). The transition from Windsor type I to III is shown in Fig. 6, which can occur due to several parameters such as salinity, surfactant concentration, and, so forth (Chan and Shah 1979).

\section{Interfacial tension (IFT)}

Interfacial tension (IFT) test was then used for further screening of the selected potential surfactant formulations which were previously selected based on their good compatibility with the sea water brine and having Type III and Type I from phase behavior test previously done. The surfactant solutions are compatible with brines when it is completely soluble with no precipitations. The IFT measurement equipment used in this study was spinning drop tension meter (SVT20 Data Physics) which can handle test temperatures up till $120^{\circ} \mathrm{C}$. Targeted IFT value for surfactant solution in EOR process is ultra-low IFT, at the range of $10^{-3} \mathrm{mN} / \mathrm{m}$ (millinewton/meter) and below, between oil and water so that oil droplet can be displaced easily due to resulting high capillary number (Wu et al. 2010).

\section{Thermal stability}

This study is designed for surfactant application in hightemperature conditions. Surfactant solution was prepared and stored in fire-sealed glass ampoule, to avoid evaporation and solution dried up. Prepared surfactant solutions were measured for their concentration, and their concentration

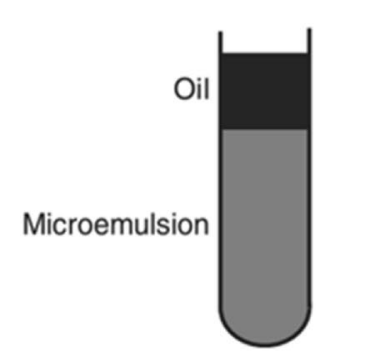

Winsor Type I microemulsion

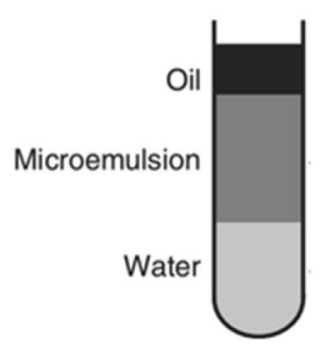

Winsor Type III microemulsion

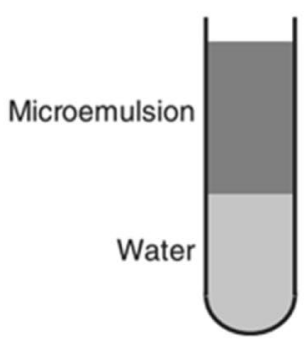

Winsor Type II microemulsion

Fig. 6 Three types of microemulsions adapted from James Sheng (2011)

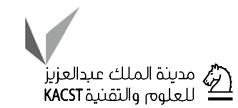


will be taken as initial concentration, in which later will be used as references in determining surfactant concentration loss over time. The surfactant solutions were tested for a long term up to 2 months for thermal stability where the surfactant solutions were aged at high temperatures $106^{\circ} \mathrm{C}$ and then the concentration, $\mathrm{pH}$, and oxygen content of surfactant solutions were measured throughout predetermined sampling days. In this step, as previously discussed in the oxygen control procedure, aging the solution at anaerobic condition is a must which was carefully provided in this work. Each ampoule containing surfactant solution was taken out from the oven to measure their concentration loss over time. Degraded surfactant concentration by thermal was measured by measuring remaining surfactant concentration, using high-performance liquid chromatography (HPLC). HPLC is a separation technique for components in the form of column chromatography that pumps a sample in a mobile phase (solvent) at high pressure through a column with a stationary phase.

\section{Surfactant adsorption investigation at high temperature}

Static adsorption was carried out to quantify the loss of surfactant by means of adsorption onto the rock. All static adsorption tests were performed in anaerobic conditions at elevated temperature. Static adsorption experiment was performed using crushed sand samples. Crushed sand samples have higher exposed surfaces area than consolidated cores and will give a worst-case value for surfactant adsorption. The sand and clay samples were sieved prior to testing. For this study, silica sand used is at the size of $250 \mathrm{~nm}$ to the $300 \mathrm{~nm}$ range, and for clays, the size range used was below than $100 \mathrm{~nm}$ size. The ratio of 1:5 of crushed sand to the chemical solution was used. The silica sand was washed with brine, and the muddy-like solution formed at the top of the solution was removed as many times as needed until a clear solution observed, as shown in Fig. 7. Then, the sand was exposed to injection brines, for overnight. The sands were dried and weighted according to predetermined weight and ratio.

Samples were stored in glass ampoules, and the dissolved oxygen in the samples was removed by vacuum and nitrogen purging of the solution for almost 2-h sequence flow. The surfactant and sand samples were aged for $24 \mathrm{~h}$ and sampled out to determine the remaining surfactant concentration. During aging, the samples are constantly agitated for every $1 \mathrm{~h}$. At sampling time, surfactant solution samples were taken out from the top of the solution, and then centrifuged the solution to separate sands and clays. The $\mathrm{pH}$ of the solution was recorded, and adsorption values were calculated by measuring the remaining surfactant concentration. The unit of chemical adsorption in the laboratory is reported as the mass of adsorbed chemical per unit mass of rock ( $\mathrm{mg} / \mathrm{g}$ rock) as given in Eq. (3). Surfactant concentration measurement was done using HPLC.

Adsorption, $\mathrm{mg} / \mathrm{g}=\frac{[\text { Initial Conc. }- \text { Final Conc. }](\mathrm{mg} / \mathrm{L}) * \text { Vol. of Solution }(\mathrm{L})}{\text { Dry Weight of Rock }(\mathrm{g})}$.

Fig. 7 Crushed silica sand washing process. a Sand with muddy-like solution while b cleaned sand after several rinses

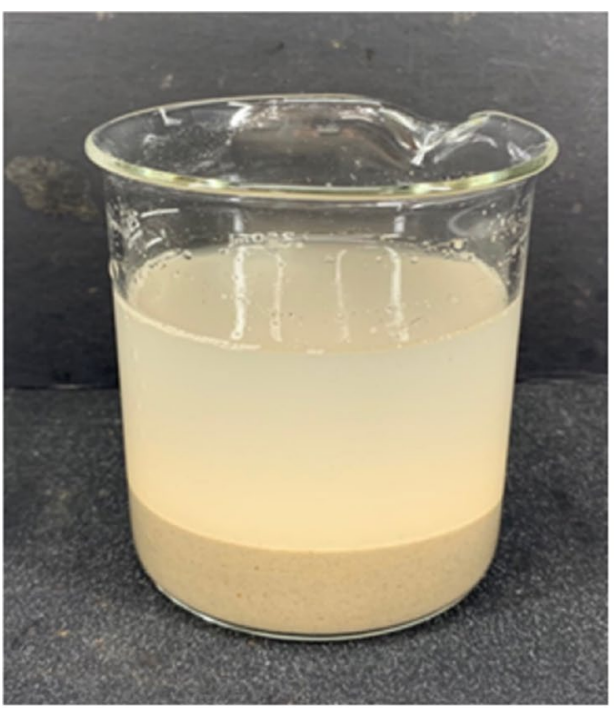

(a)

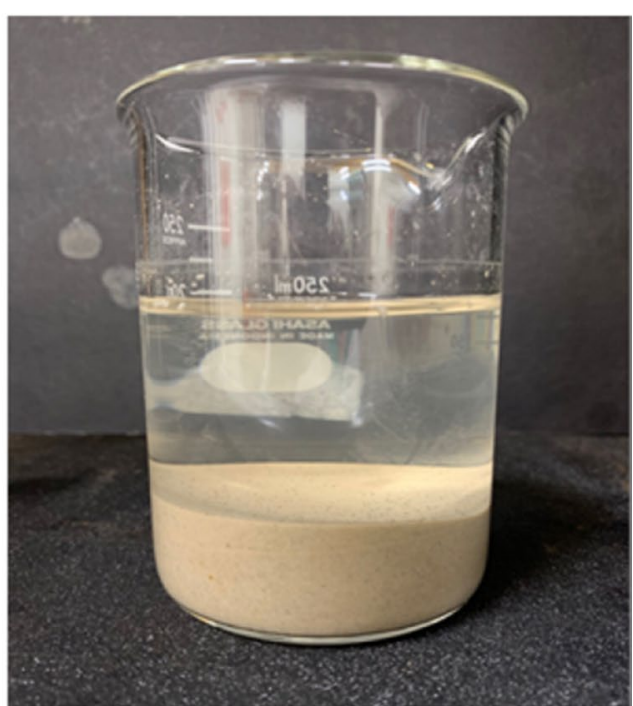

(b)

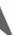


Fig. 8 Common surfactant type's compatibility and solubility, at $25^{\circ} \mathrm{C}$

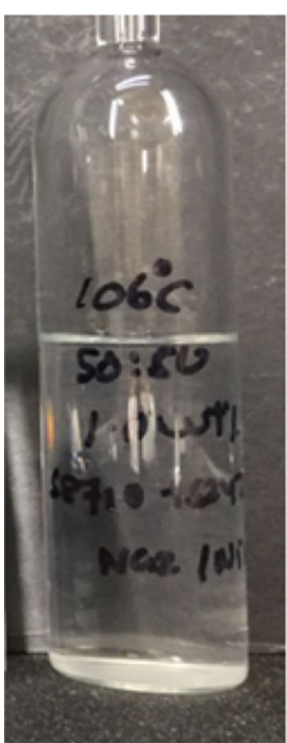

(a)

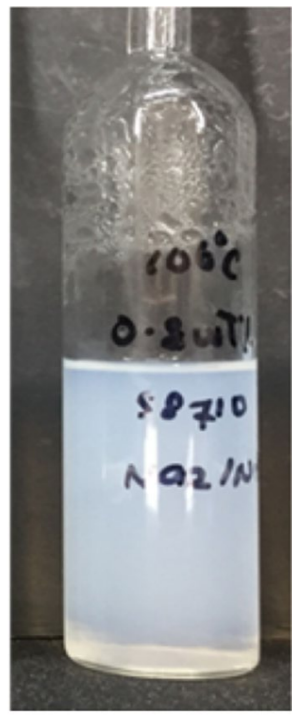

(b)
Fig. 9 Solubility test a clear surfactant solution and b cloudy surfactant solution

\section{Results and discussion}

\section{Solubility and compatibility at high temperature}

Three types of surfactant were tested for its solubility in seawater brine at ambient conditions for a preliminary screening. Figure 8 shows their solubility and compatibility. It is clearly seen that sulfonate-type surfactants precipitate in seawater brine, due to its sensitivity to divalent ions present in the brines. On the other hand, sulfate surfactant shows very good solubility. However, Shupe (Shupe 1978) in his patent explained that sulfate linkage in the molecular structure of surfactant causes the molecules to be highly sensitive to temperature. This results in hydrolysis or other permanent degradation of the molecules to a non-reactive form. Therefore, surfactants with sulfate units are not suitable for formations with high temperatures. Thus, carboxylate-type surfactant was proceeded for further evaluation at high temperature (Fig. 9).

Alvares (Jurgenson et al. 2015) reported that using AEC alone at harsh condition might not meet required surfactant performance criteria. Thus, co-surfactant is needed to enhance surfactant performance, especially solubility. Therefore, single-surfactant AEC and blend of AEC and APG surfactant formulations at various concentrations and ratio were tested for solubility and compatibility with sea water at a baseline temperature of $80{ }^{\circ} \mathrm{C}$ and reservoir temperature of $106{ }^{\circ} \mathrm{C}$. All samples were prepared using sea water as brine and aged at a predetermined temperature in sealed glass ampoules containing no oxygen. Then, surfactant solubility and compatibility were assessed, and nonsoluble composition will be identified if the surfactant solution showed cloudiness, phase separation, and precipitation.
Table 4 Summary result for surfactant solubility at various concentrations and blending ratio after 60 days at $106^{\circ} \mathrm{C}$

\begin{tabular}{llllllll}
\hline Surfactant blend composition & \multicolumn{7}{l}{ Total surfactant concentration (wt\%) } \\
\cline { 2 - 8 } & 0.05 & 0.1 & 0.2 & 0.4 & 0.6 & 0.8 & 1 \\
\hline AEC & Clear & Clear & Cloudy & Cloudy & Cloudy & Cloudy & Cloudy \\
AEC + APG (ratio 80:20) & NA & Clear & Cloudy & Cloudy & Cloudy & Cloudy & Cloudy \\
AEC + APG (ratio 70:30) & NA & Clear & Cloudy & Cloudy & Cloudy & Cloudy & Clear \\
AEC + APG (ratio 60:40) & NA & Cloudy & Clear & Clear & Clear & Clear & Cloudy \\
AEC + APG (ratio 50:50) & NA & Clear & Clear & Clear & Clear & Clear & Clear \\
\hline
\end{tabular}

$N A$ test did not perform at this condition 
Table 5 Summary result for surfactant solubility at various overall concentrations and blending ratio after day 60 days at $80{ }^{\circ} \mathrm{C}$

\begin{tabular}{llllllll}
\hline Surfactant blend composition & \multicolumn{2}{l}{ Total surfactant concentration $(w t \%)$} \\
\cline { 2 - 9 } & 0.05 & 0.1 & 0.2 & 0.4 & 0.6 & 0.8 & 1 \\
\hline AEC & Clear & Clear & Cloudy & Clear & Cloudy & Cloudy & Cloudy \\
AEC + APG (ratio 80:20) & NA & Clear & Clear & Clear & Clear & Clear & Clear \\
AEC+APG (ratio 70:30) & NA & Clear & Clear & Clear & Clear & Clear & Clear \\
AEC + APG (ratio 60:40) & NA & Clear & Clear & Clear & Clear & Clear & Clear \\
AEC + APG (ratio 50:50) & NA & Clear & Clear & Clear & Clear & Clear & Clear \\
\hline
\end{tabular}

$N A$ test did not perform at this condition
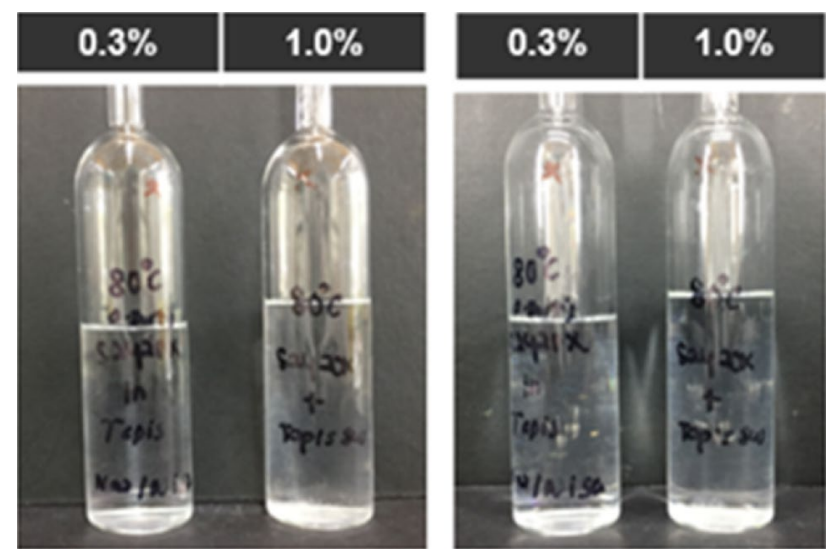

Fig. 10 APG surfactant compatibility and solubility at $0.3 \%$ and 1.0 wt $\%$ concentration, at $80^{\circ} \mathrm{C}$ after 30 days (left) and 60 days (right)

Tables 4 and 5 show the summary results for surfactant solubility after 60 days at $106^{\circ} \mathrm{C}$ and $80^{\circ} \mathrm{C}$, respectively In these tables, a word of clear indicates that the surfactant solution appearance is clear and no precipitation or cloudiness was observed (Fig. 10a) and cloudy means that the surfactant solution became cloudy and was not compatible with the injection seawater brine (Fig. 10b).

Results show that surfactant solubility behavior differs at a high temperature of $106{ }^{\circ} \mathrm{C}$ as compared to the baseline temperature of $80{ }^{\circ} \mathrm{C}$. At $106^{\circ} \mathrm{C}$, most of the samples became cloudy and showed the sign of incompatibility with the sea water. This cloudiness is coming from the fact that oxygen bond in the surfactant chemical structure can be affected, due to oxidation by increasing the temperature above $80{ }^{\circ} \mathrm{C}$. Therefore, it makes surfactant molecules become less water soluble, thereby changing the partitioning coefficient (Bevlere et al. 1988). At $80^{\circ} \mathrm{C}$, surfactant blend is too hydrophilic and, therefore, showed good compatibility with brine, thereby producing only normal emulsion with no tendency to form a microemulsion phase. On the one hand, the cloudiness reported at $80{ }^{\circ} \mathrm{C}$ for AEC surfactant alone (Table 5) shows that using a co-surfactant is a must when good compatibility with the sea water is desired. On the other hand, it is still extremely difficult dealing with the harsh condition of high-temperature and high-salinity/

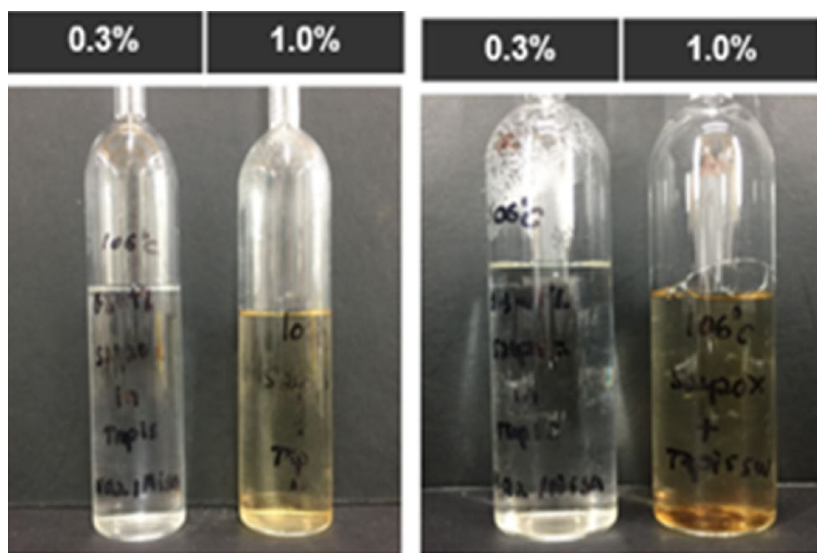

Fig. 11 APG surfactant compatibility and solubility at $0.3 \%$ and 1.0 wt $\%$ concentration, at $106{ }^{\circ} \mathrm{C}$ after 30 days (left) and 60 day (right)

hardness conditions even with co-surfactant application, since several blend surfactant formulations showed incompatibility at high temperature. Table 4 also shows that changing the surfactant/co-surfactant ratio can help to find an optimum ratio, for this case (50:50 for AEC + APG, respectively), which can result in a compatible formulation for high-temperature application.

APG alone was also tested to check APG stability as co-surfactant at high temperature. Figure 10 shows that the APG solution is stable at $80{ }^{\circ} \mathrm{C}$ even after 60 days for both concentrations of 0.3 to 1.0 weight $\%$. However, APG surfactant at a high temperature of $106{ }^{\circ} \mathrm{C}$ encounters color changing and phase separation, as evidenced by Fig. 10, which can be the main cause of instability observed in the blending surfactant formulation in $106^{\circ} \mathrm{C}$. The color change of the APG solution to yellowish at $106{ }^{\circ} \mathrm{C}$, which was clearly observed at high concentration of APG, is possibly due to the degradation of APG at high temperature. Therefore, APG is only recommended to be used as co-surfactant in the high-temperature application at optimum ratio and lower concentration to enhance the solubility of the main surfactant in the sea water (Fig. 11). 
Fig. 12 Phase behavior of formulations of a AEC surfactant only and b AEC with APG at ratio 50:50 at $106^{\circ} \mathrm{C}$ at seawater brine. Total surfactant concentration increases from left to right from $0.2 \mathrm{wt} \%$ to $1.0 \mathrm{wt} \%$

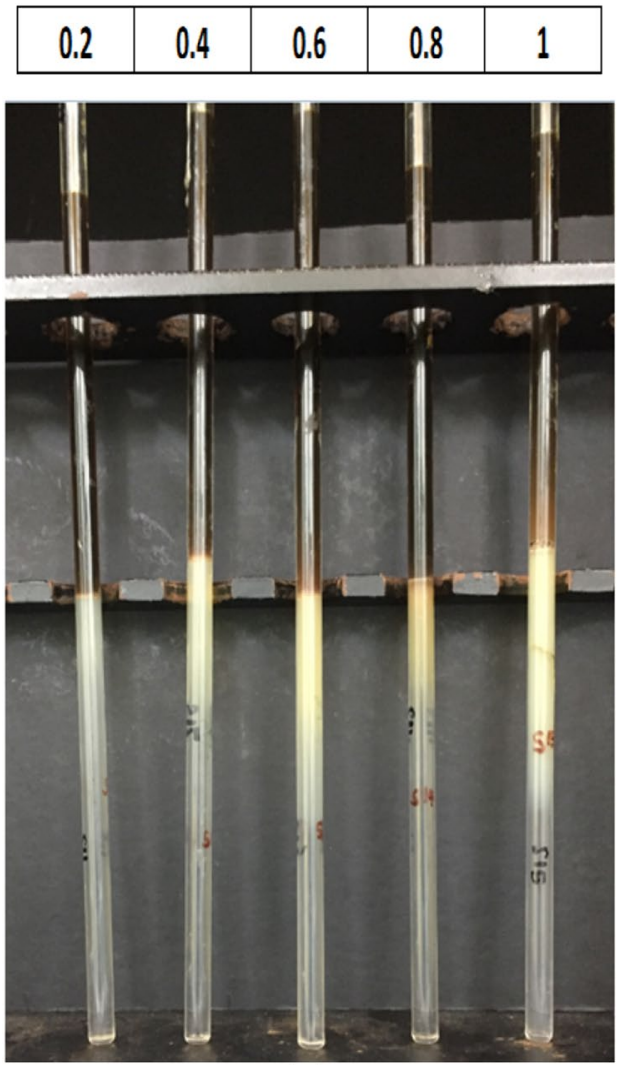

(a)

\begin{tabular}{|l|l|l|l|l|}
\hline 0.2 & 0.4 & 0.6 & 0.8 & 1 \\
\hline
\end{tabular}
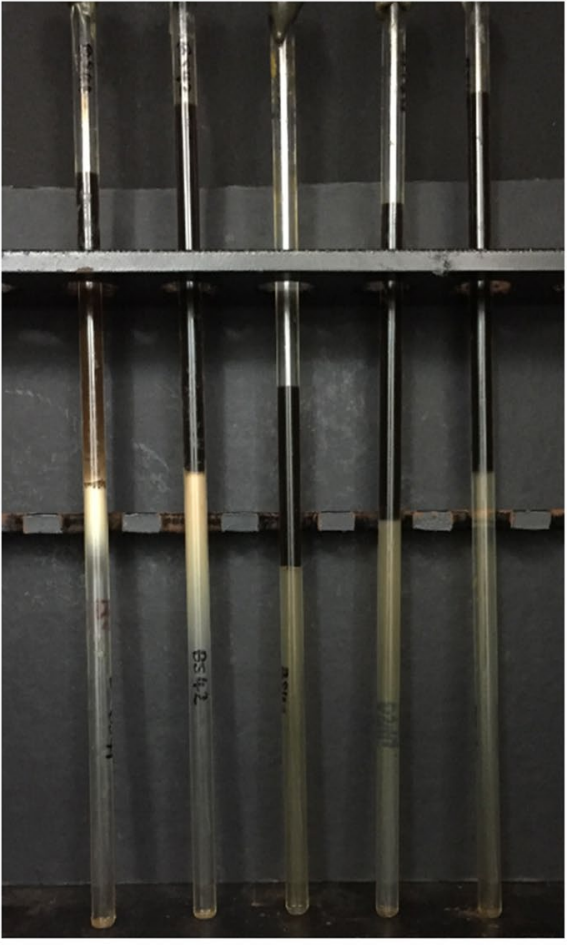

(b)

\section{Phase behavior}

Microemulsion phase behavior test of single-component AEC and a blending formulation of AEC with APG at an optimum mixing ratio of 50:50 were also performed in this work. Different surfactant concentrations prepared with seawater brine and tests were performed at an elevated temperature of $106{ }^{\circ} \mathrm{C}$, and the microemulsion produced was monitored visually until the mixture system equilibrates. Figure 8 shows the result of this test for a range of surfactant concentration from $0.2 \%$ to $1.0 \mathrm{wt} \%$. On the one hand, Windsor type III was produced for all concentrations of single AEC, although cloudiness can be observed in the brine phase, as shown in Fig. 12a. It also shows that AEC is a robust surfactant, as it is able to reduce interfacial tension and produce microemulsion phase at low concentration of 0.2 to $1.0 \mathrm{wt} \%$. However, only two low concentrations of $0.2 \mathrm{wt} \%$ and $0.4 \mathrm{wt} \%$ showed Windsor type III behavior for blending of AEC and APG at optimum ratio, as shown in Fig. 12b. At a concentration of $0.6 \mathrm{wt} \%$ to $1.0 \mathrm{wt} \%$ for blend formulation, surfactant becomes more hydrophilic and shows Windsor type I.

\section{IFT measurement}

Results of the IFT test are presented in Fig. 13. The figure shows that AEC surfactant alone at a concentration range of $0.4 \mathrm{wt} \%$ to $1 \mathrm{wt} \%$ is able to lower down the interfacial tension to approximately $10^{-3} \mathrm{mN} / \mathrm{m}$ region at $106^{\circ} \mathrm{C}$. Therefore, it has good performance and high interfacial activity at high temperature. This low IFT result is expected since based on phase behavior microemulsion test, type III Windsor was observed for the same surfactant solutions concentration range. However, the range of surfactant concentration that results in optimum condition from the two tests of phase behavior and IFT cannot be directly compared because oilto-water ratio in phase behavior test is 100 times higher than the IFT test. Therefore, a shift of optimum concentration is expected between these two tests.

Based on the solubility test, using AEC alone will be risky as the solution may face cloudiness and, in some cases, even may encounter surfactant precipitation problem. Therefore, the addition of co-surfactant to enhance solubility might become a necessity. Figure 13 also shows the IFT behavior of the blend formulation of surfactant and co-surfactant as a function of total surfactant concentration at $106{ }^{\circ} \mathrm{C}$ and expressed that ultra-low IFT (at region $10^{-3} \mathrm{mN} / \mathrm{m}$ ) is achieved at a low surfactant concentration 
Fig. 13 Interfacial tension, $\mathrm{mN} / \mathrm{m}$ of $\mathrm{AEC}$ and AEC/APG surfactant at different concentrations at $106{ }^{\circ} \mathrm{C}$ in seawater salinity brine
IFT Measurement

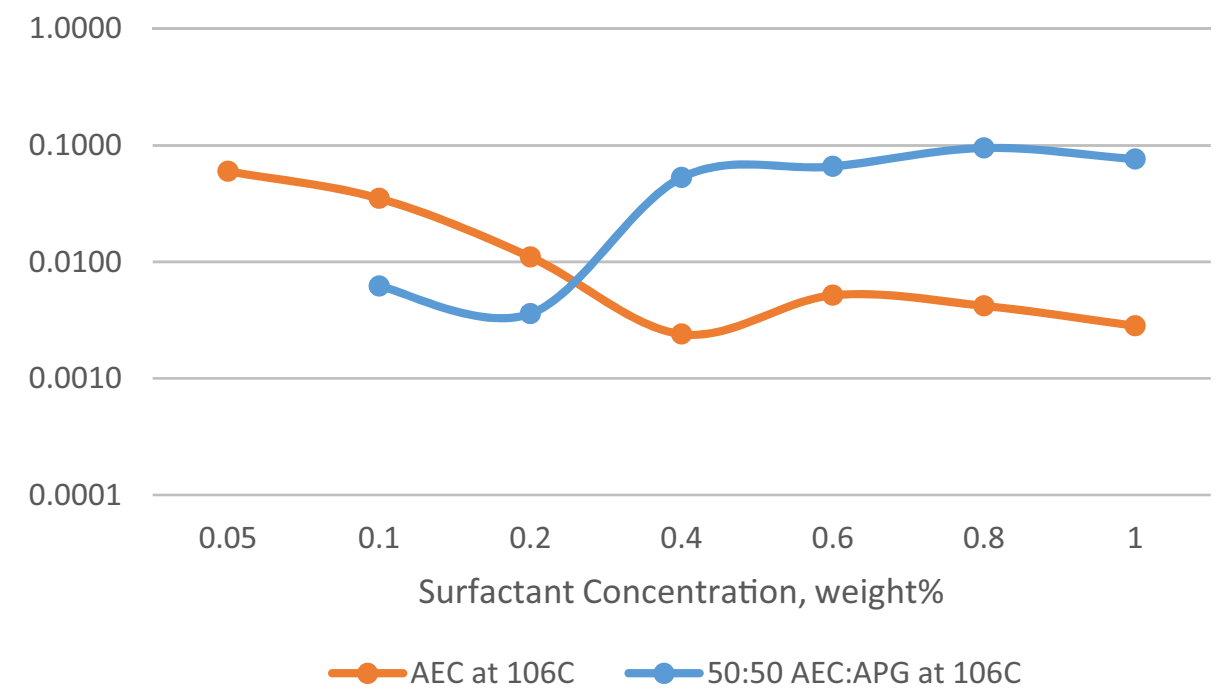

of blend formulation ( $0.1 \%$ to $0.2 \mathrm{wt} \%) .2000 \mathrm{ppm}$ is the concentration where the lowest IFT is observed for blending surfactant formulation.

\section{Effect of thermal on surfactant performance}

The remaining concentration in the targeted environment represents a criterion for any chemicals to be used. Continuous aging of the displacing fluid is detrimental to EOR. For this reason, prolonged thermal stability tests were conducted for selected surfactant in the injection brines. The surfactant solutions were evaluated for their stability to maintain their concentrations throughout the aging time. Dissolved oxygen is also measured for all samples, to ensure that the surfactant solutions were kept in anaerobic condition. This step is crucial since surfactant must be in free oxygen condition, as oxygen is such a concern. Organic molecules can be sensitive to oxygen at high temperatures. In reservoir, oxygen is not a problem since injection fluids are degassed. All blending AEC/APG solutions were observed yellowish (due to APG color) but clear in solutions, while AEC surfactant was observed slightly cloudy when prepared. Initial concentration prepared for both surfactant solutions (AEC and AEC/ APG) is at $1.0 \mathrm{wt} \%$. Figure 14 shows the results for the thermal stability of the surfactant solution in seawater brines at $106^{\circ} \mathrm{C}$. From the graph, it is clearly seen that after 60 days, both surfactant solutions maintained their concentrations at $1.0 \mathrm{wt} \%$. The experimental accuracy of the HPLC method is around $2 \%$, which in this case equals to $0.02 \mathrm{wt} \%$. Surfactant peak was qualitatively the same as the original samples, thus showing that no degradation was observed. For AEC surfactant, even though the surfactant concentration maintained, it is clearly seen that the surfactant solution turns cloud over the aging time. Blending AEC/APG surfactant was observed to have no degradation, and clear solution was observed but with a higher intensity of yellowish solution,
Fig. 14 Surfactant thermal degradation at $106^{\circ} \mathrm{C}$ in seawater salinity brine

\section{Surfactant thermal degradation in seawater brines at}

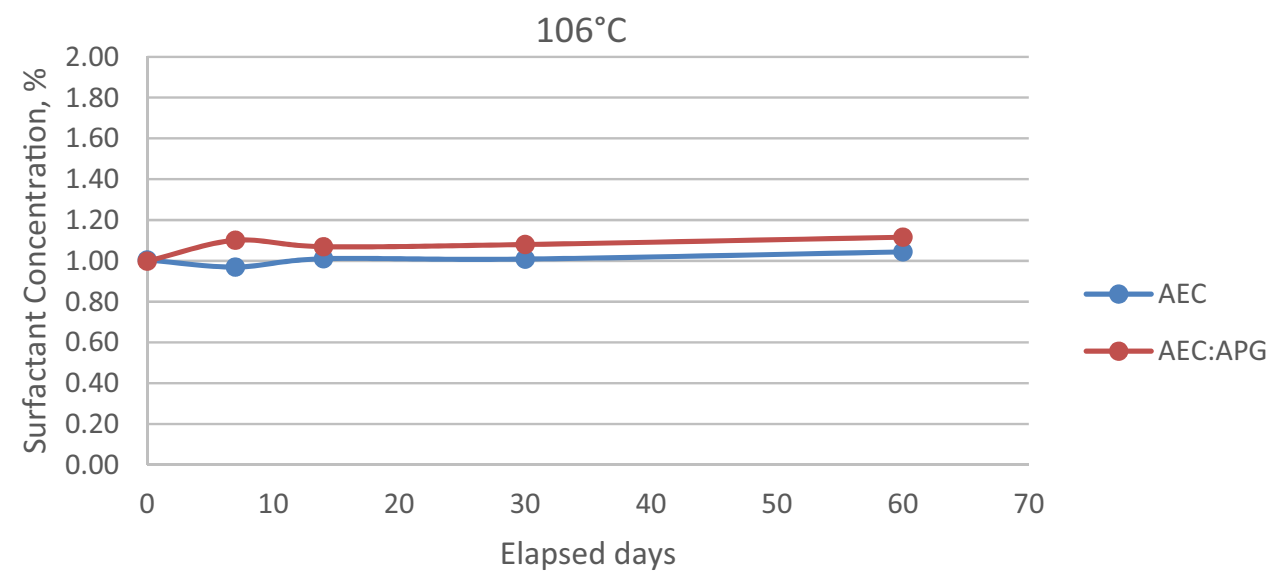


Fig. 15 Adsorption relationships due to the temperature effect

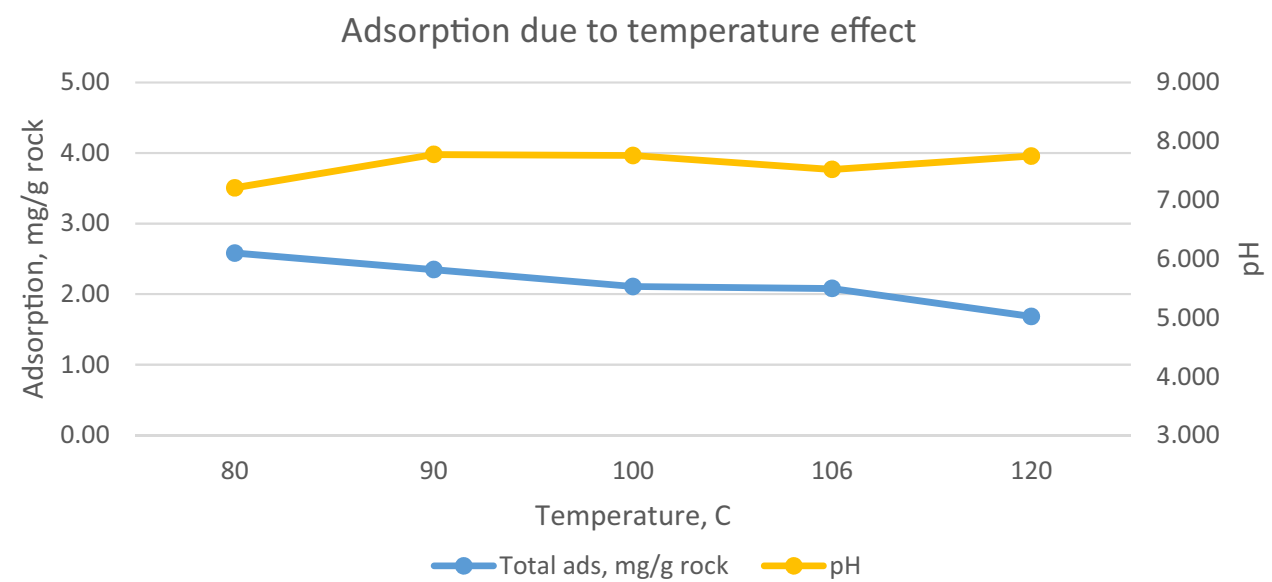

reduction in solubility, and compatibility up to 60 days of observation. This is believed due to the initial concentration of the solution that is too high, $1.0 \mathrm{wt} \%$.

\section{Temperature effects on surfactant adsorption}

The high-temperature condition with more than $100{ }^{\circ} \mathrm{C}$ is the primary focus of this study. Therefore, adsorption behavior in the high-temperature region was studied, and the adsorption trend was observed. For adsorption, temperature region was investigated at a range of 80 to $120^{\circ} \mathrm{C}$. Based on the previous study, most of the adsorption test was done at room temperature (mostly $25^{\circ} \mathrm{C}$ ). Thus, this study was done to confirm the adsorption behavior in the high-temperature region. Figure 15 shows surfactant adsorption trends due to the temperature effect. For this investigation, clay content and mineralogy, salinity and surfactant concentration were fixed, by using reservoir conditions. For this specific experiment, it is very important to clearly distinguish between thermal and adsorption effect. Thus, all samples were measured in relation to controlled samples, to exclude the thermal degradation effect. Adsorption loss measured is purely due to surfactant adsorption to solid surface.

Surfactant adsorption trends were observed in the high-temperature region, up to a tested temperature of $120{ }^{\circ} \mathrm{C}$. Surfactant adsorption slightly decreases as the temperature increases from 80 to $120{ }^{\circ} \mathrm{C}$. Temperature increase generally causes a decrease in the efficiency and effectiveness of ionic surfactant. However, the change is relatively small compared to that caused by $\mathrm{pH}$ change (Rosen 2004). That is why most of the time, changing the solution $\mathrm{pH}$ to higher than surface point zero of charge is favorable to reduce surfactant adsorption. However, there is still an interest to identify and understand surfactant adsorption due to the temperature effect. The ionic surfactant efficiency decreases when temperature increases, because at high temperature, physical bonding to the surface is weaker; thus, it is anticipated that surfactant adsorption decreases when temperature increases and this study proved the relationship. Solubility means surfactant has stronger bonding in water, and it has been observed that at high temperature, the solubility decreases, which indicates that the bonding to water is weaker, thus supporting lower adsorption at high temperature.

Surfactants used are an anionic surfactant, which is the preferred surfactant type used for EOR process to minimize surfactant adsorptions at sandstone reservoir. $\mathrm{pH}$ is the prominent factor that contributes to the charge on the mineral colloids (Paria and Khilar 2004). In sandstone, the surface charge is typically positive at lower $\mathrm{pH}$ and decreases to a negative value at higher $\mathrm{pH}$. The $\mathrm{pH}$ value at which the net charge on the surface is zero is termed a point of zero charges. In this experiment, the $\mathrm{pH}$ of the aqueous solution was measured after adsorption test, and there is not much change in $\mathrm{pH}$ for surfactant solution at different temperatures.

\section{Surfactant adsorption: surfactant separation}

Carboxylate surfactant is used as the main surfactant in this study, and at high temperature, head of the surfactant molecule dissociates more, which turns the solution into carboxylic acids. Figure 16 shows that carboxylate surfactant adsorption is relatively higher than APG surfactant. This observation can be related to the chemical structure for carboxylate and APG surfactant. APG surfactant chain is suspected to be shorter than carboxylate surfactant. Longer surfactant tail prefers to adsorb on the solid surface. That is why AEC surfactant adsorbs more compared to APG surfactant. 
Fig. 16 Surfactant separation for adsorption due to temperature effects
Adsorption due to temperature effects : Surfactant

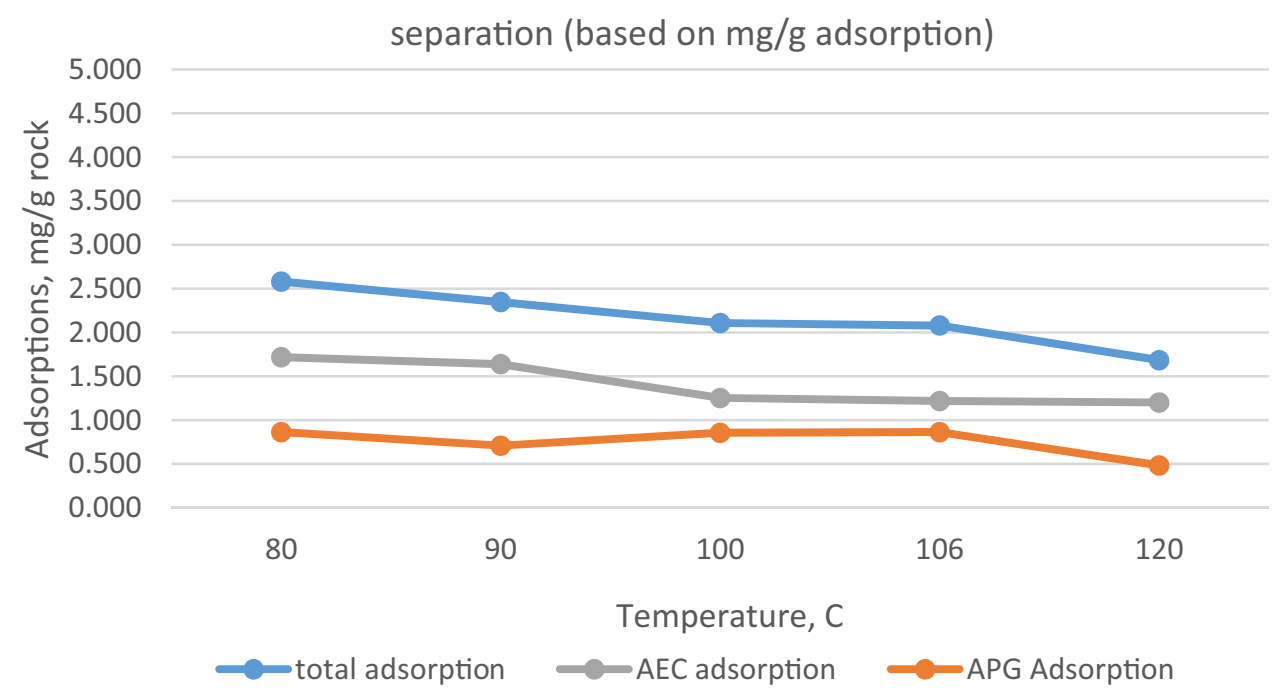

This assumption is supported by the properties and observations of the APG that the solution density is water like; thus, shorter tail is expected. In addition, AEC is a viscous surfactant solution; therefore, longer tail is expected.

\section{Conclusion}

The aim of this study was to find a specific surfactant formulation to be stable at a temperature as high as $106^{\circ} \mathrm{C}$ and using sea water as a solvent (fixed salinity/hardness condition). The selected surfactant formulation was then evaluated for the surfactant adsorption behavior at high-temperature and high-salinity/hardness conditions. Based on the present study, the following conclusion can be made:

- Single-surfactant system such as modified alkyl ether carboxylate (AEC) was not capable of meeting performance criteria required for harsh environment (high-temperature/salinity/hardness conditions). Therefore, a blend formulation (surfactant and co-surfactant) is required for such extreme conditions.

- It has been found that a blend formulation with a ratio of 50:50 of AEC and a modified alkyl polyglucoside (APG) is capable of passing solubility and phase behavior test and also provides ultra-low interfacial tension. The proposed formulation can provide a possibility to implement chemical EOR at a condition of a high temperature of $106^{\circ} \mathrm{C}$ and using sea water as injection water.

- Generally, to assess surfactant performance for EOR, surfactant fluid analysis was performed, and surfactant formulations must be compatible to injection brine at reservoir temperature, fulfill surfactant mechanism for
EOR application by achieving type III microemulsion, and able to reach ultra-low IFT and stable for long term.

- Surfactant loss due to adsorption decreases at increasing temperature. This phenomenon is mainly due to weaker physical bonding to surface at high temperature; thus, decrease in surfactant adsorption was observed when temperature increases.

- This finding provides guidelines for surfactant adsorption study for high-temperature application, where the temperature impact for surfactant adsorption is not significant. And maximum surfactant adsorption occurred at low temperatures.

Open Access This article is distributed under the terms of the Creative Commons Attribution 4.0 International License (http://creativeco mmons.org/licenses/by/4.0/), which permits unrestricted use, distribution, and reproduction in any medium, provided you give appropriate credit to the original author(s) and the source, provide a link to the Creative Commons license, and indicate if changes were made.

\section{References}

Abbas AH, Wan Sulaiman WR, Zaidiljaafar M, AugustineAja A (2017) Anionic surfactant adsorption: insight for enhanced oil recovery, pp $0-4$

Adkins S, Arachchilage G, Solairaj S, Lu J, Weerasooriya U, Pope G (2012) Development of thermally and chemically stable largehyrdrophobe alkoxy carboxylate surfactant. In: SPE154256, Tulsa Oklahama, 14-18 April

Akbari S, Mahmood SM, Tan IM, Onn LL, Hosein G (2017) Effect of aging, antioxidant, and mono- and divalent ions at high temperature on the rheology of new polyacrylamide-based co-polymers. Polymers. https://doi.org/10.3390/polym9100480

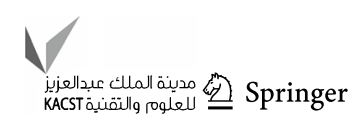


Bevlere M, Bazin B, Noik C (1988) Surfactant for EOR: olefin sulfonate behavior at high temperature and hardness 3:597-603

Chan KS, Shah DO (1979) The effect of surfactant partitioning on the phase behavior and phase inversion of the middle phase microemulsions. In: SPE-7869-MS

Chatzis I, Morrow N (1984) Correlation of capillary number relationship for sandstone. SPEJ Soc Pet Eng J 24(5):555-562

Dabrowski A (2001) Adsorption from theory to practice. Adv Colloid Interface Sci 93(1):135-224

Hadian N, Syed N, Hamed MM (2018) A rigorous approach to analyze bulk and coreflood foam screening tests. J Pet Explor Prod Technol 9:809-822

Hamed H, Syed M, Mahmood Negar H, Khaled A (2018) Foam flow in porous media: concepts, models and challenges. J Nat Gas Sci Eng 2018:163-180

Hematpur H, Mahmood SM, Akbari S, Nasr NH (2017) Comparison study on anionic surfactants and mixed surfactant behavior in SAG foam process. In: Awang M, Negash B, Akhir NM, Lubis L, Rafek AM (eds) ICIPEG 2016. Springer, Singapore

Hesham A, Mahmood SM, Al-Mutarreb A (2018) Effect of anionic surfactant on wettability of shale and its implication on gas adsorption/desorption behavior. Energy Fuels 32(2):1423-1432

Hocine S, Cuenca A, Magnan A, Tay A, Moreau P, The EOR Alliance, Solvay (2016) An extensive study of the thermal stability of anionic chemical EOR surfactant-stability in aqueous solutions. In: IPTC-18974-MS

Jun L, Sriram SPJ, Stephanie A, Gayani P, Do HK, Christopher B, Upali W, Pope GA (2014) New surfactant development for chemical enhanced oil recovery. J Pet Sci Eng 120:94-101

Jurgenson GA, Bittner C, Kurlal-Siebet V, Oetter G, BASF SE; J. Tinsley BASF Corp. (2015) Alkyl ether carboxylate surfactants for chemically enhanced oil recovery in harsh field conditions. In: SPE-174589-MS, SPE asia pacific enhanced oil recovery conference, Kuala Lumpur, Malaysia, 11-13 August 2015

Kamal MS, Hussein IA, Sultan AS (2017) Review on surfactant flooding: phase behavior, retention, IFT, and field applications. Energy Fuels 31(8):7701-7720

Lu J, Britton C, Solairaj S, Liyanage PJ, Kim DH, Adkins S, Arachchilage GWP, Weerasooriya U, Pope GA (2014) Novel largehydrophobe alkoxy carboxylate surfactants for enhanced oil recovery. In: SPE-154261, SPE improved oil recovery symposium, Tulsa, Oklahoma, USA, 14-18 April 2014

Morel D, Al-Amri O, Delattre E, Cordelier P, Greder H, Rivero M, Romero C, Bursaux R, Peltier S, Levitt D (2016) Specific procedure for an offshore chemical EOR one spot pilot in a high salinity high temperature environment. In: SPE-181643-MS, SPE annual technical conference and exhibition, Dubai, 26-28 September 2016

Paria S, Khilar KC (2004) Areviewon experimental studies of surfactant adsorption at the hydrophilic solid-water interface. Adv Colloid Interface Sci 110:75-95

Puerto M, Hirasaki GJ, Miller CA, Barnes JR (2012) Surfactant systems for EOR in high temperature, high salinity environments. In: SPE-129675-PA

Rosen MJ (2004) Surfactant and interfacial phenomena-characteristics features of surfactant. 3rd edn, pp 2-24

Schramm LL (2000) Surfactant: fundamentals and applications in the petroleum industry. Cambridge University Press, Cambridge

Sheng J (2011) Modern chemical enhance oil recovery: theory and practice. Gulf Professional, London

Shupe RD (1978) Surfactant oil recovery process usable in high temperature formations containing high salinity water. Google Patents

Southwick JG, van Rijn CHT, van den Pol E, van Batenburg DW, Shell Global Solutions, Manap AA, PETRONAS Research Sdn Bhd (2016) Surfactant flooding in offshore environments. In: SPE-179642-MS

Wu Y, Iglauer S, Shuler P, Tang Y, Goddard WA (2010) Branched alkyl alcohol propoxylated sulfate surfactants for improved oil recovery. Tenside, Surfactants, Deterg. https://doi.org/10.2118/7869-MS

Zhou M, Zhao J, Wang X, Yang Y (2013) Research on surfactant flooding in high temperature and high salinity reservoir for enhanced oil recovery. Tenside, Surfactants, Deterg. https://doi. org/10.3139/113.110245

Publisher's Note Springer Nature remains neutral with regard to jurisdictional claims in published maps and institutional affiliations. 